\title{
América Latina vista por la prensa marroquí: El caso del periódico Al-Ittihad Al-Ichtiraki
}

\author{
Latin America Seen by the Moroccan Press: \\ The Case of the Al-Ittihad Al-Ichtiraki Newspaper
}

\author{
Hiri Abdelhak \\ Es doctor en Lengua y Literatura Hispánica por la Universidad Hassan II Casablanca (Marruecos). \\ Profesor titular en el Instituto Superior Internacional de Turismo de Tánger (ISITT) \\ Email: hiriest@hotmail.com.
}

Doi: https://doi.org/10.22267/rceilat.214849.95

\section{Resumen}

El objetivo principal de esta investigación es poner de manifiesto cómo está informado el lector marroquí de América Latina y los latinoamericanos a través del periódico marroquí Al-Ittihad Al-Ichtiraki Para su análisis se va a trabajar con una de las herramientas metodológicas más utilizadas en las ciencias sociales como es el análisis de contenido. El segundo objetivo de este estudio, está relacionado con el posicionamiento de estas informaciones. Se trata de analizar las características técnicas de la información: si es noticia de portada, si está firmada, si se han utilizado fuentes nacionales o no, etc.

Palabras claves: Representación; América Latina; Análisis de contenido; Al-Ittihad Al-Ichtiraki

\begin{abstract}
This research claims to reveal the image of Latin America in the Moroccan press, specifically in the newspaper Al Ittihad Al Ichtraki. The main purpose of this research is to investigate the associated representation of Latin America of this press by using different methods such as qualitative, thematic, and stylistic. The main objective can be defined as to explain motivations that make the press to lead that representation. The second objective of this study, related to the first, is to study the position of this information. Therefore, during this research analyzing methodology has been used to qualitificate, measure and accomplish by conclusions.
\end{abstract}

Key words: Representation; Latin America; The Moroccan press; Al-Ittihad Al-Ichtiraki

\section{Introducción}

Marruecos y América Latina, a pesar de la distancia geográfica, están ligados, desde tiempos inmemoria- les, por vínculos histórico-culturales, comparten muchos aspectos comunes de confluencia y en las últimas décadas han construido relaciones amistosas y fructíferas. Este tipo de vínculos 
permite explorar la manera en que ambos espacios geográficos representan al otro en sus propios medios, ya que la representación mediática de los países es cada vez más un factor de gran relevancia en sus mutuas relaciones. De las palabras dichas anteriormente se infiere la necesidad de contar con un análisis de las imágenes que proyecta la prensa marroquí de América Latina. La presente investigación constituye un primer paso en esta dirección. Se trata de estudiar el tratamiento informativo ofrecido por la prensa escrita marroquí al tema argentino. Concretamente, tratamos de analizar el tratamiento informativo de América Latina en la prensa marroquí en diferentes momentos y en diferentes periódicos marroquíes.

El presente trabajo propone una investigación de carácter exploratorio y descriptivo el tratamiento informativo de América Latina en el mapamundi periodístico marroquí. Nuestro propósito, pues, es poner de manifiesto cómo está informado el lector marroquí de América Latina y de los latinoamericanos a través de la prensa escrita marroquí. Partimos de la base de que los medios de comunicación de prensa ejercen una notable influencia sobre la opinión pública porque gran parte del conocimiento que tenemos acerca del mundo que nos rodea emana de los medios de comunicación. En este sentido, cabe citar la opinión de Cándido Monzón, quien establece un tipo de relación causa-efecto entre los medios de comunicación y opinión pública:

La opinión pública ha encontrado siempre en los medios de comuni- cación su mejor medio de expresión [...] Las opiniones son de los públicos, pero su publicidad está en los medios, de aquí que siga oyéndose en la actualidad que la opinión pública es lo que dicen los medios de comunicación (Citado por Ramírez, 2005, p.177).

Atendiendo a la precisión anterior, podemos inducir que los medios se constituyen como mediadores que se encargan de transmitir y marcar las opiniones. En otros términos, lo que llamamos opinión pública es el reflejo de un proceso de un conjunto de ideas expresadas por los medios de comunicación.

\section{Metodología}

Con el propósito de conocer la representación informativa de América Latina en el periódico marroquí Al-Ittihad Al-Ichtiraki hemos visto oportuno realizar esta investigación desde la modalidad del análisis más utilizado en las ciencias sociales como es el análisis de contenido. El académico Bernand Berlson lo define como:

Una técnica de investigación para la descripción sistemática, objetiva y cuantitativa del contenido manifiesto de la comunicación (Berelson, 1952, p.18).

De esta manera, podemos sintetizar que el análisis de contenido es una técnica que permite explicar y sistematizar el contenido de los mensajes comunicativos. Hemos decidido apostar por esta herramienta metodológica porque nos resulta una herramienta útil para conocer las pautas generales del interés mediático de la prensa marroquí sobre 
Argentina. Por lo tanto, la metodología que aplicamos fue primordialmente cuantitativa, con el análisis cualitativo.

De esta manera, podemos sintetizar que el análisis de contenido es una técnica que permite explicar y sistematizar el contenido de los mensajes comunicativos. El corpus de análisis lo representa un total de 669 noticias publicadas en el diario Al-Ittihad Al-Ichtiraki, que representa toda la producción editorial que el diario objeto de estudio publica sobre América Latina, durante el periodo que va del 1 de enero de 1991 a diciembre de 2015. Curiosamente el espacio temporal estudiado coincide con una etapa en la cual se profundizó el acercamiento entre América Latina y Marruecos y, consecuentemente, el afianzamiento de los lazos de cooperación entre ambos países.

Para la realización efectiva de este marco metodológico, será necesario seguir un estudio y unas etapas claramente definidas y unas reglas estrictas que nos permitan aprovechar al máximo todo el material estudiado. Primeramente, hemos comenzado nuestra investigación realizando una búsqueda hemerográfica a fin de recopilar como muestra los textos noticiosos que hacen referencia a América Latina en un período de veinticinco años. Una vez recopilado el corpus bruto del análisis, el paso siguiente consiste en ingresarlo en un documento Excel para crear una base de datos. Esta herramienta de Microsoft Office permite filtrar y ordenar de una manera cronológica la información según variables de manera separada, lo que permite contabilizarla y extraer los resultados que veremos más adelante.

Lo que justifica la elección de este medio es que representa a los principales grupos periodísticos nacionales de Marruecos. Al-Ittihad Al-Ichtiraki (La Unión Socialista), es un periódico marroquí publicado en árabe, aparece el 21 de junio de 1988. Este órgano periodístico recibía el nombre de Al-Moharrir, pero después de sufrir un arresto, se vio obligado a cambiar de nombre, así pasó a ser llamado Al-Ittihad Al-Ichtiraki como un portavoz del partido de La Unión Socialista de Fuerzas Populares (USFP). Desde esta fecha, la dirección y la responsabilidad política del periódico fueron concedidas a Mohammed El Brini. Este diario representa el portavoz que divulga la ideología de los militantes del partido Unión Socialista de Fuerzas Populares (USFP). Según los datos de las estadísticas del Organismo de justificación de la difusión (OJD) publicados en su sitio Web www.ojd.ma. En 2015, su difusión fue de 5725 ejemplares.

El objetivo de este enfoque es ofrecer una serie de cuestiones básicas del corpus, tales como la evolución cronológica de las unidades informativas, los temas encontrados en el corpus, el género periodístico utilizado en los textos periodísticos, el autor o los autores de las unidades informativas y la página en la que está ubicada. Con ello se procura caracterizar el corpus en sus aspectos más básicos y facilitar algunos argumentos complementarios para el análisis de contenido. Los datos que se ofrecen aspiran a una repre- 
sentación lo más precisa posible de la visibilidad informativa de América Latina en el periódico marroquí Al Ittihad Al Ichtiraki. Para ello, se realizará un minucioso análisis estadístico con el fin de elaborar cuadros y gráficos que nos permitan sacar conclusiones de nuestra investigación.

En líneas generales, la metodología utilizada se enmarca en tres etapas: primero, una selección de las piezas comunicativas (recogida de información que hace referencia a América Latina); segundo, la elaboración y la categorización del corpus, y tercero, el análisis de los resultados y las conclusiones principales.

\section{Resultados obtenidos}

Los contenidos del presente estu- dio describen y analizan la totalidad de las publicaciones informativas que el diario Al-Ittihad Al-Ichtiraki hizo de América Latina, durante el período que va desde el año 1991 hasta 2015. Con este trabajo pretendemos analizar los distintos aspectos formales y cuantitativos de la presencia del subcontinente latinoamericano en el periódico objeto de estudio.

\section{Evolución cronológica de las uni- dades comunicativas}

En este primer capítulo se exponen las piezas identificadas del conjunto de la producción editorial publicada en un espacio temporal que va desde 1991 hasta 2015. El siguiente gráfico recoge la distribución de las distintas noticias aparecidas en función de su evolución cronológica:

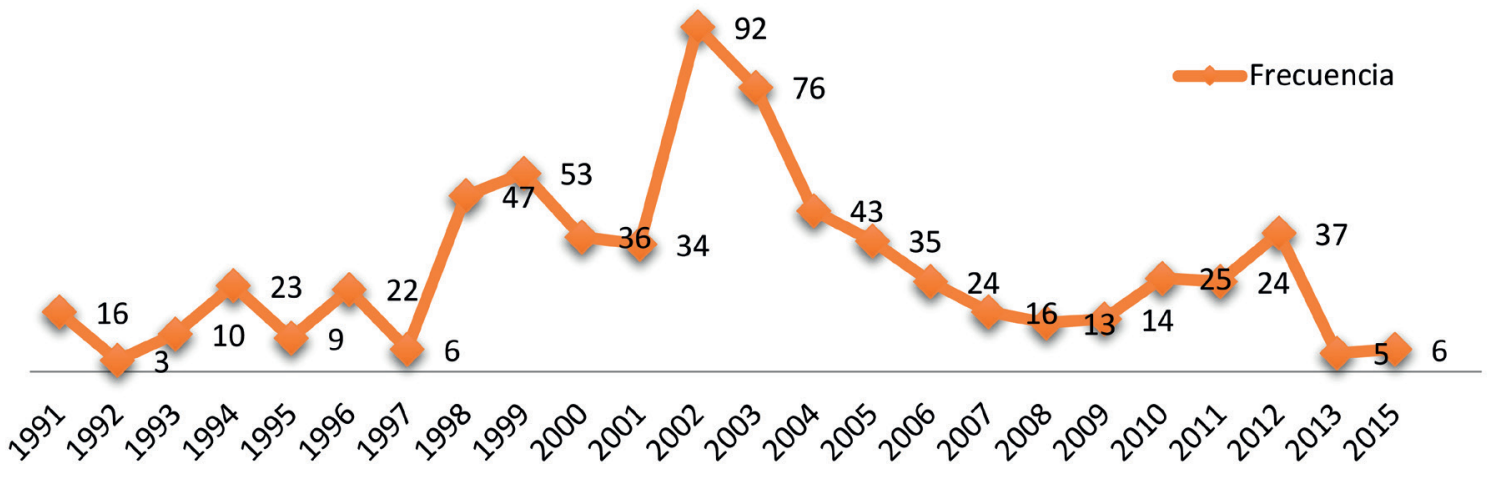

Gráfico 1. Evolución cronológica de las unidades informativas. Fuente: elaboración propia.

A la vista de la evolución cronológica de las unidades informativas podemos observar lo siguiente:

Una de las primeras aproximaciones que se puede plantear es la idea de que el mundo latinoamericano tiene una cobertura informativa no- toriamente deficiente en las páginas del diario Al Ittihad-Al-Ichtiraki. Así, a partir del análisis del corpus, podemos observar que, durante el período establecido de veinticuarto años, la cantidad de informaciones publicadas en el diario objeto de estudio ha abarcado un total de 669 unidades 
comunicativas. Por tanto, la muestra es lo suficientemente representativa para extraer ciertas conclusiones. Una de las primeras conclusiones que se impone es la idea de que la agenda mediática del diario Al-Ittihad AlIchtiraki, como un periódico marroquí en árabe y de difusión nacional, presta muy poca atención informativa al subcontinente latinoamericano.

No obstante, en el gráfico se puede apreciar que la distribución de las unidades analizadas (669 unidades comunicativas) no resulta equilibrada, ya que se observa una notoria discriminación informativa en la distribución anual de las unidades comunicativas. En otros términos, hay años en los que la producción informativa está cargada y, en cambio, otros años resultan poco noticiosos. Por consiguiente, no todos los años son representados igualmente en cantidad ni en calidad. Algunos se consideran más relevantes mientras hay otros que presentan una frecuencia ínfima.

Desde una perspectiva diacrónica, se constata que la cobertura informativa del tema latinoamericano, en el período que va de 1998 a 2000, alcanza unos niveles muy altos. No obstante, la proporción de informaciones en el resto de los años tiende a bajarse. Esta situación podría ser explicada por la idea de que, durante dicho marco temporal, el diario objeto de estudio recoge en sus páginas algunas informaciones que aluden a las dinámicas diplomáticas emprendidas por parte del Gobierno marroquí hacia algunos países de América Latina.

A partir de ahí, podemos deducir que este hallazgo establece una relación de causa-efecto. Así, a medida que se produce un acercamiento a nivel de la acción exterior del Gobierno marroquí hacia América Latina, mayor es su incidencia a nivel de la cobertura del diario objeto de estudio. Este hecho se refuerza al tomar en cuenta que el espacio temporal señalado coincide con la toma del poder del partido de La Unión Socialista de Fuerzas Populares (1998-2002), del que el diario objeto de estudio es considerado su voz periodística. Esta situación implicaría que la agenda de información latinoamericana responde a intereses gubernamentales. Con el objeto de tener una visión global de la evolución cronológica de las unidades informativas, presentaremos a continuación un análisis de todos los artículos publicados desde una perspectiva temática.

\section{Clasificación temática general}

En el presente apartado tratamos de mostrar de manera más específica qué tipo de temas predominan en la información sobre América Latina. Con este estudio de la temática pretendemos conocer cuáles son los temas que el diario Al-Itihad Al-Ichtiraki selecciona y comparte con sus lectores. A continuación se muestra el siguiente gráfico que permite establecer un estudio comparativo entre los diversos temas encontrados en el corpus: 


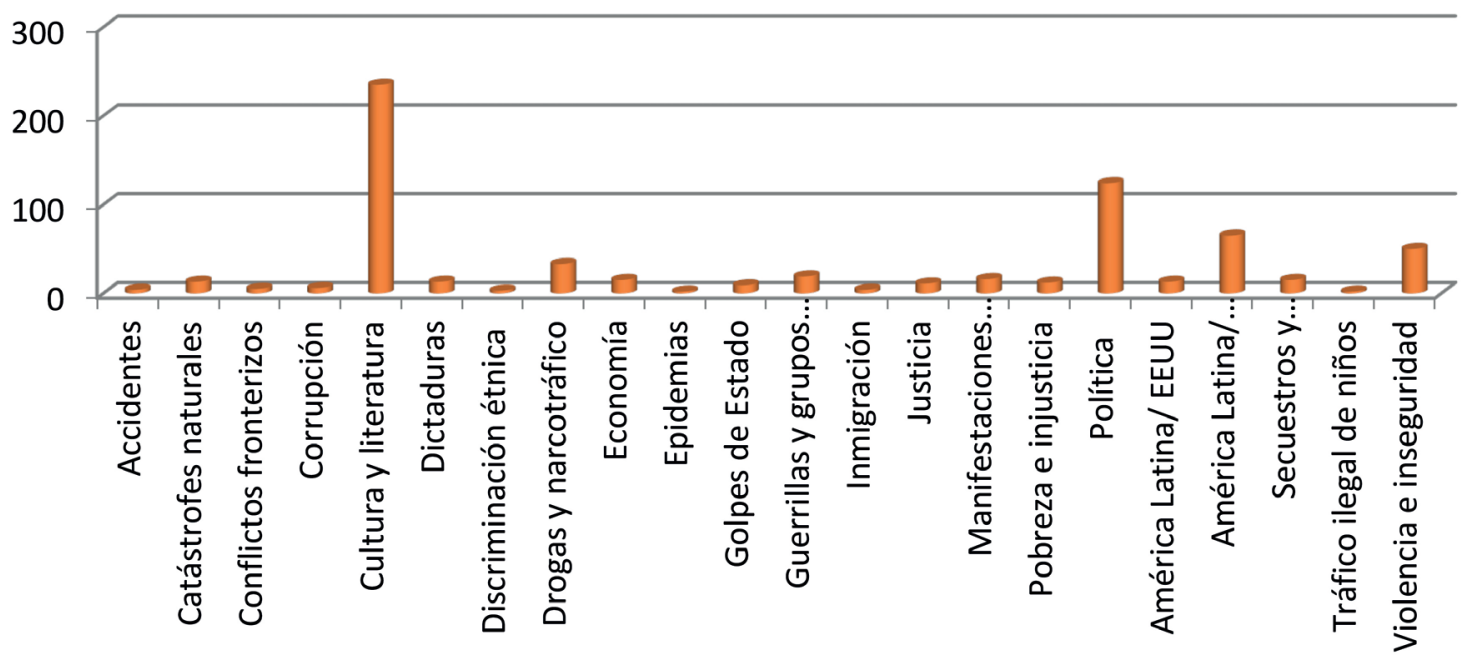

Gráfico 2. Los temas encontrados en el corpus. Fuente: elaboración propia.

A la vista de las evidencias obtenidas en la representación gráfica, podemos observar la gran cantidad y variedad de temas noticiosos con respecto a América Latina. No obstante, el análisis muestra que el tratamiento temático con respecto a América Latina no resulta más equilibrado, ya que se constata un notorio desequilibrio.

En efecto, el análisis muestra que el tema con mayor incidencia en el diario Al-Ittihad Al-Ichtiraki es el de la cultura; este asunto suma un total de 669 unidades comunicativas. Es, de hecho, la temática que más se repite, genera mayor interés y es uno de los asuntos al que dedica más espacio. Aunque hemos percibido una elevada cantidad de ejemplos significativos que aluden a dicho eje temático, las piezas identificadas se circunscriben en términos generales a aspectos relativos a la literatura latinoamericana. Este dato es muy revelador; denota que el diario objeto de estudio presenta un tratamiento informativo muy po- sitivo del subcontinente latinoamericano. De lo cual, podemos asumir que los lectores del periódico Al-Ittihad Al-Ichtiraki, tenían más posibilidades de apreciar este subcontinente como espacio con una gran riqueza literaria. Este hecho se refuerza al tomar en consideración que el órgano periodístico estudiado reserva un espacio destacado a las grandes figuras literarias latinoamericanas. En las páginas del periódico estudiado podemos leer los siguientes titulares:

$$
\begin{aligned}
& \text { باتك عمل مه وتنيمر اسو تلر آ سيخروب }
\end{aligned}
$$

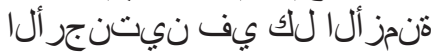

Borges, Arlt y Sarmiento los mejores escritores de Argentina de todos los tiempos (Traducción nuestra). (Al-Ittihad Al-Ichtiraki, 14/09/1993, última página)

ياو غور أل نم بتاك :يتيدينيب ويرام Mario Benedetti escritor uruguayo. (Al-Ittihad Al-Ichtiraki, 27/06/1994, última página) 
مات نينح رزيكر ام ايسر اغ ليبيربغ La luminosa nostalgia de García Márquez. (Al-Ittihad Al-Ichtiraki, 30/05/1994, última página)

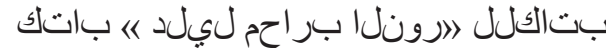

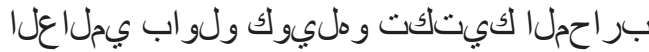

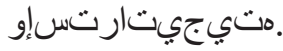

Manual del Guerrero de la Luz” del escritor más universal Paulo Coelho, Tácticas y estrategias de combate. (Al-Ittihad Al-Ichtiraki, 03/07/2003, p.5)

ةريسو ةابيح ةريس صبيخروب سيول يخروخ

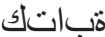

Antología e itinerario literario de Jorge Luis Borges (Al-Ittihad Al-Ichtiraki, 10/12/2003, p.2)

حرفلاو حرجلا عبانم : ثابويفاتكو أ.

Octavio Paz: las fuentes de la herida y la alegría. (Al-Ittihad Al-Ichtiraki, 11/06/2004, p.1)

$$
\begin{aligned}
& \text { بحل ثبيوابوط ةبيؤر ـ وهليوك ولواب } \\
& \text { سن جلاو }
\end{aligned}
$$

Paulo Coelho: visión utópica del amor y del sexo. (Al-Ittihad Al-Ichtiraki, 12/08/2004, p.6)

(1974/1899) سايرتسا لبيجنأ لي غئيم ثيسنرف نويعب 197/1899) Miguel Ángel Asturias (1974/1899): América Latina vista por los franceses. (Al-Ittihad Al-Ichtiraki, 0807/2011, p.11)

El segundo tema con mayores valores noticiosos es la política; este asunto recibe una privilegiada atención informativa en el diario objeto de estudio. El análisis demuestra la presencia de un total de 123 textos periodísticos que hacen alusión a este aspecto temático. Algo lógico, toman- do en consideración que el órgano periodístico objeto de estudio, es considerado la voz periodística del partido político marroquí (USFP). De hecho, podemos inferir que los factores ideológicos priman para este tipo de tratamiento informativo. Sobre la naturaleza de estas piezas informativas notamos por una parte varias unidades informativas en las que se aprecia una declarada simpatía política hacia los diferentes movimientos políticos de la izquierda latinoamericana. Por otra, implica que el diario objeto de estudio ofrece una mayor visibilidad informativa a las grandes dinámicas políticas de la agenda electoral latinoamericana. A manera de ilustración veamos los siguientes titulares:

ةنسلا تاقاق حتسا قبينيتال

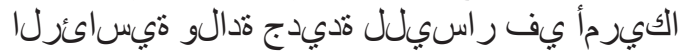

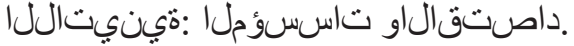
El nacimiento de una nueva izquierda en América Latina: Elecciones presidenciales de América Latina, instituciones y economía. (Al-Ittihad Al-Ichtiraki, 14-15/01/2006, p.6)

$$
\begin{aligned}
& \text { ةمز أب رذنب نيتن }
\end{aligned}
$$

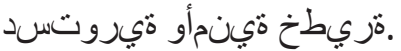

Vacío político en Argentina augura una grave crisis constitucional y de seguridad. (Al-Ittihad Al-Ichtiraki, 02/01/2002, p.1)

سولر اك سيئرل افلخ راتخت نيتن جر أل

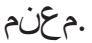

Argentina elige al sucesor de Carlos Menem (Al-Ittihad Al-Ichtiraki, 25/10/1999, p.3)

$$
\text { ير اسئل طسولاب زوفي فلاحت حشرم :يليشل }
$$


Chile: un candidato de la coalición centro-izquierda gana la presidencia. (Al-Ittihad Al-Ichtiraki, 13/12/1993, p.1)

El tercer tema en la escala de los resultados hace referencia a eventos relacionados con intereses y acciones diplomáticas recíprocas entre Marruecos y algunos países latinoamericanos. Es de apuntarse que la llegada en 1998 de un Gobierno de alternancia, bajo la presidencia del socialista Abderrahman El Youssoufi, hizo que las miradas informativas del órgano periodístico se dirigiesen hacia América Latina. En otros términos, la llegada de los socialistas al Gobierno ha tenido una vocación informativa preferencial por el área latinoamericana. Veamos los siguientes titulares:

$$
\begin{aligned}
& \text { هتر ايز دعب نيتنجر ألاب لحي يفسويلا } \\
& \text { ييليش ايشل }
\end{aligned}
$$

El Yousssoufi llega a Argentina tras su visita a Chile. (Al-Ittihad Al-Ichtiraki, 14/03/2000, p.1)

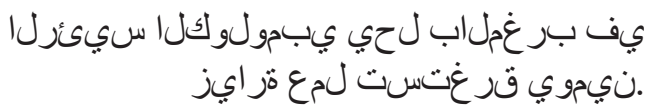

El presidente colombiano emprende una visita de trabajo a Marruecos que durará dos días. (Al-Ittihad Al-Ichtiraki, 17/103/1999, p.1).

Aparte de las referencias informativas a las relaciones diplomáticas de Marruecos con América Latina, el diario objeto de estudio hizo una especial cobertura a la postura que mantienen algunos países latinoamericanos con respecto a la cuestión del Sáhara marroquí. A este propósito, ilustramos los siguientes titulares:

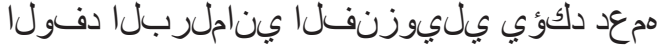

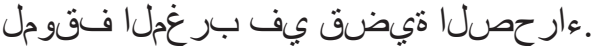 La delegación parlamentaria vene- zolana afirma su apoyo a la tesis marroquí en relación a la cuestión del Sáhara. (Al-Ittihad Al-Ichtiraki, 14/04/2001, p.1)

$$
\begin{aligned}
& \text { ىمسي ام عم اهتاقالع دمجت ياو غار ابلا }
\end{aligned}
$$

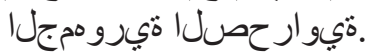 \\ Paraguay congela sus relaciones con la pseudo RASD. (Al-Ittihad Al-Ichtiraki, 05/05/2000, p.1)}

Otro tema noticioso es la violencia. Este asunto suma un total de 50 unidades informativas que, de manera directa o indirecta, estaban relacionadas con la violencia, lo que representa el $7,47 \%$ de las noticias analizadas. Sobre la naturaleza de estas unidades informativas, el análisis sintetiza que dichas informaciones hacen referencia a la delincuencia y los homicidios. A manera de ilustración veamos los siguientes titulares:

$$
\begin{aligned}
& \text { قوفت ثينيت التا الكيرمأ يف مئرارجلا }
\end{aligned}
$$

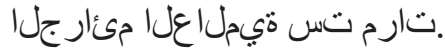

Los crímenes en América Latina superan seis veces la tasa media mundial. (Al-Ittihad Al-Ichtiraki, 22/04/1998, última página)

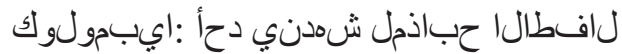
Colombia: a nadie le sorprende el asesinato de los niños.(Al-Ittihad Al-Ichtira$k i, 11 / 04 / 1993$, p.1)

Luego, en su orden, aparece el tema de las drogas y el narcotráfico, con una cobertura recurrente; este asunto deja un resultado de 33 unidades informativas. Esta situación, a nuestro entender, maltrata y daña la 
imagen del subcontinente latinoamericano, porque presenta una imagen prejuiciosa y retrata un espacio sumergido en las drogas y narcotráfico. Ilustramos los siguientes titulares a modo de ejemplo:

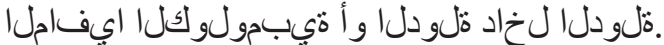

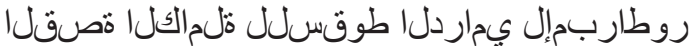

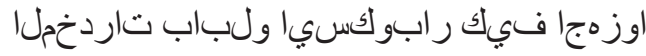

$$
\begin{aligned}
& \text { ميلع اوزماج }
\end{aligned}
$$

La historia completa de la caída dramática de Pablo Escobar, el emperador de las drogas, ¿cómo lo han matado? (Al-Ittihad Al-Ichtiraki, 13/02/1994, p.6)

Le sigue en importancia de frecuencia, el tema de las guerrillas y los grupos paramilitares. Sobre la naturaleza de las piezas seleccionadas, el estudio muestra que los textos periodísticos relativos a este asunto enfatizan el Conflicto de Chiapas o Conflicto chiapaneco transcurrido entre el Gobierno de México y la guerrilla del Ejército Zapatista de Liberación Nacional (EZLN). Así, en las páginas del periódico objeto de estudio podemos leer el siguiente titular:

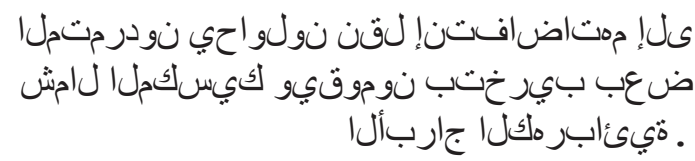

Los grupos rebeldes están tratando de mover su rebeldía hacia el Norte de México y están saboteando algunas torres eléctricas. (Al-Ittihad Al-Ichtiraki, 01/11/2004, p.3)
Otro tema que adquiere una notoriedad informativa en las páginas del diario Al-Ittihad Al-Ichtiraki es el de los secuestros y los desaparecidos. El análisis suma un total de 15 unidades referidas a este asunto. Ilustramos el ejemplo del siguiente titular:

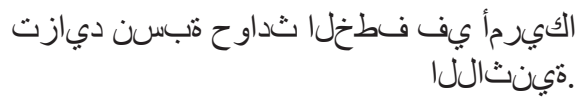

Aumentan los secuestros en América Latina. (Al-Ittihad Al-Ichtiraki, 25/06/1995, p.1).

Llama poderosamente la atención que el tema económico suma apenas un total de 15 titulares noticiosos. Este hecho demuestra el desinterés del periódico por las cuestiones económicas latinoamericanas.

A continuación presentamos los resultados cuantitativos del resto de los temas tratados en el periódico Al-Ittihad Al-Ichtiraki en función de su presencia: las relaciones América Latina/Estados Unidos acapara un total de 13 unidades comunicativas. Los golpes de Estado incluyen 9 unidades informativas. La corrupción es otro campo temático que aglutina un total de 6 titulares informativos. En los penúltimos puestos en la escala del tratamiento temático figura el tema de los conflictos fronterizos. Finalmente los últimos puestos lo ocupan, respectivamente, el tema de la inmigración y los accidentes con 4 titulares; epidemias y tráfico ilegal de niños, con 2 titulares respectivamente.

A partir de lo analizado podemos llegar a la conclusión de cómo el tratamiento temático gira en torno a temá- 
ticas preferentemente culturales y políticas donde llama poderosamente la atención el tratamiento positivo que se da a las noticias sobre América Latina y los latinoamericanos. Si bien es cierto que se presentan algunos aspectos negativos, sobre todo, en cuestiones de violencia e inseguridad, estas imágenes pierden mucha presencia informativa a favor de asuntos culturales y políticos. Una vez comentados los temas, damos un paso más sobre los géneros periodísticos.

\section{Los géneros periodísticos utilizados}

Nuestra atención se centra ahora en estudiar el estilo con el que son tratados los diversos temas estudiados. El análisis de los géneros periodísticos arroja los siguientes resultados:

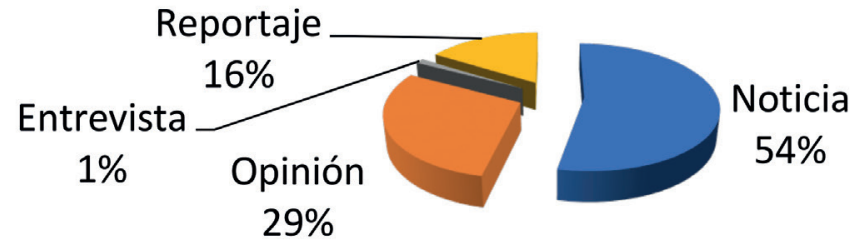

Gráfico 3. Distribución porcentual de los géneros periodísticos. Fuente: elaboración propia.

A tenor de los resultados obtenidos, podemos observar que en el conjunto de las 669 unidades analizadas, un total de 357 piezas comunicativas corresponden al género informativo. De hecho, podemos afirmar que la noticia, sin lugar a dudas, es el género predominante. A una considerable distancia aparecen el resto de las variables.

El segundo género periodístico de mayor incisión es el de opinión: se han hallado 179 unidades (el 29\%) que encajan dentro de la descripción de este género. Este dato es de relevancia considerable, ya que supone un tratamiento relativamente más profundo del tema latinoamericano. En proporciones similares se han registrado reportajes (31 unidades, el $11 \%)$ y menor es la presencia de la entrevista en la cobertura de los 11 sucesos seleccionados (sólo 8 unidades, el
$1 \%)$. En cuanto a la naturaleza de las piezas analizadas, el análisis revela que este género periodístico es instrumentalizado para exponer el quehacer literario latinoamericano.

En definitiva, la tendencia es la elaboración de textos informativos. La valoración que emana de estos datos es de un trabajo de redacción con poco análisis que requiera una investigación desde una dimensión analítica.

\section{Origen geográfico de la información}

Nuestra atención se centra ahora en identificar los países latinoamericanos que suscitan mayor interés mediático del periódico objeto de estudio. En el siguiente gráfico encontramos la representación porcentual que refleja la aparición de cada país en el total de las piezas analizadas: 


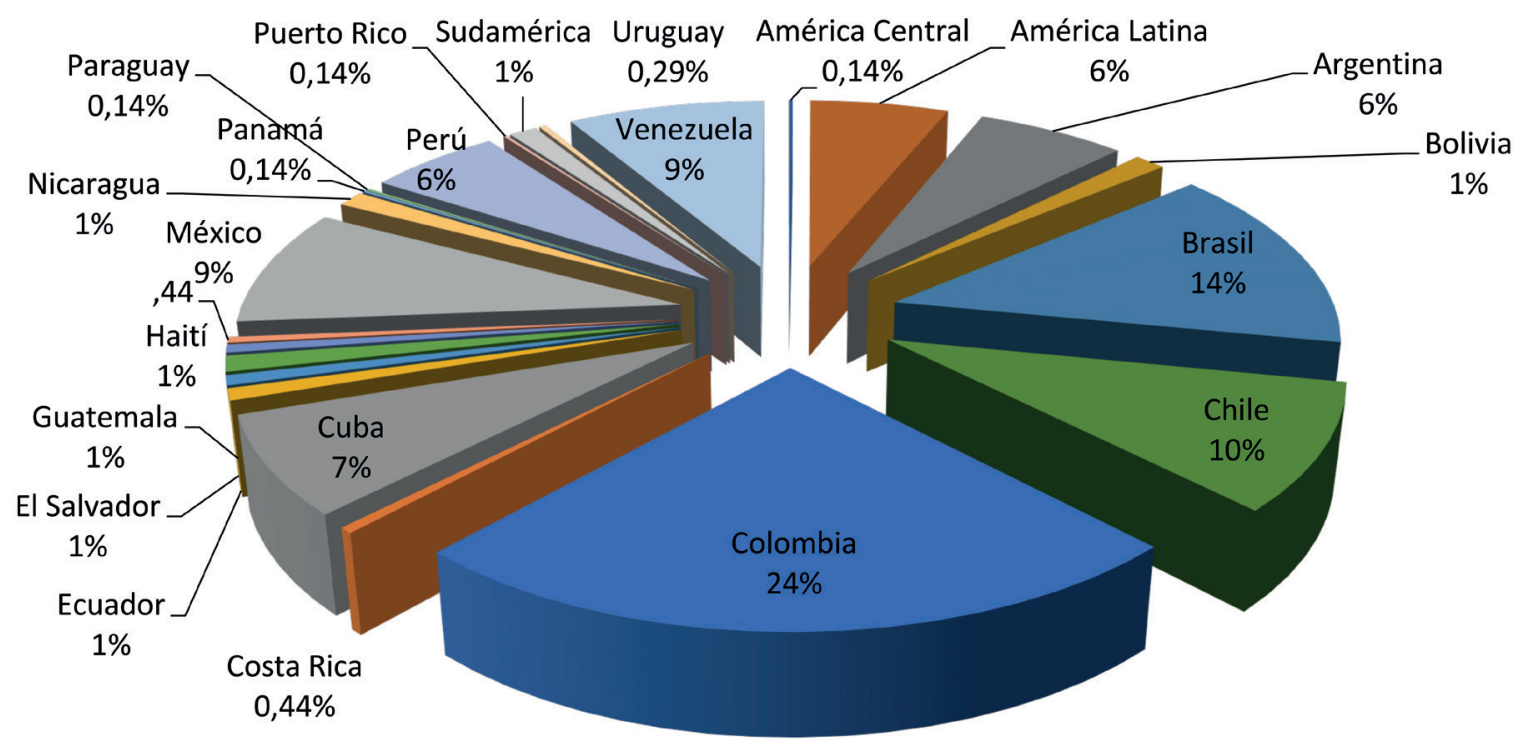

Gráfico 4. Distribución porcentual de las unidades por áreas geográficas.

Fuente: elaboración propia.

Las evidencias arriba expuestas ponen de relieve el grado de dispersión informativa: hay una polarización homogénea de áreas geográficas que generan información, o sea, hay países en los que la producción informativa está cargada; y en cambio, otros espacios resultan inanes a estos efectos. Esto significa que no todos los países son representados igualmente en cantidad ni en calidad. Algunos se consideran más relevantes mientras hay otros que pueden considerarse desiertos mediáticos por no encontrar información sobre ellos. Así, en el aparato de los países protagonistas de las unidades informativas analizadas destacan Colombia, Brasil, México, Venezuela y Chile.

El primer país que aparece como origen de información latinoamericana es Colombia. Es origen de un número muy elevado de informaciones. En concreto, este país suramericano aglutina un total de 163 unidades comunicativas, lo que representa el 24,36\% de la información estudiada. Su protagonismo queda palpable en muchas de las informaciones estudiadas. Cabe destacar que el diario Al-Ittihad Al-Ichtiraki retrata a este país suramericano, por una parte, como un foco de atención constante de conflictos con las guerrillas y los grupos paramilitares. Por otra, el diario objeto de estudio pone el acento sobre una de las figuras más emblemáticas de la literatura universal. Se trata del escritor y periodista colombiano Gabriel García Márquez.

Los siguientes valores más altos corresponden a Brasil. Este país suramericano acapara un total de 95 unidades comunicativas. En relación a la naturaleza de dichas piezas informativas, se nota que el periódico objeto de estudio retrata a este país suramericano, por un lado, como un país con grandes recursos culturales; y por otro, como uno de los países con que Marruecos mantiene una relación histórica y diplomática. 
Significativamente destaca México que recibe un emplazamiento más privilegiado en las páginas del diario objeto de estudio. Este país centroamericano incluye un total de 70 unidades comunicativas en las que el nombre de México aparece como titular, con un porcentaje que alcanza el $8,96 \%$, lo que reflejaría la tendencia de dar mayor visibilidad a dicho país en las informaciones de esta cabecera en cierto sentido.

Por su parte, Venezuela ocupa una posición privilegiada en la escala de los resultados: incluye un total de 57 unidades comunicativas, lo que representa el 8,52\% de la muestra.

El quinto país con mayores valores noticiosos es Chile, éste recibe un tratamiento privilegiado en la agenda mediática del órgano periodístico estudiado. Así, el análisis permite apreciar que dicho país aglutina el 9,56\% del corpus estudiado. Una información de vital importancia, el diario objeto de estudio recupera en sus páginas una de las partes más trágicas de la historia chilena, se trata de la historia del Golpe Militar de 1973, que derrocó al Presidente Salvador Allende y el Gobierno de la Unidad Popular. En este mismo sentido, destacamos que el periódico Al-Ittihad Al-Ichtira$k i$, publica una serie de unidades comunicativas traducidas al árabe de un libro que recibe el título de El Último Día de Salvador Allende, cuyo autor es Oscar Soto Guzmán, médico personal del que fuera presidente de Chile Salvador Allende. En estas unidades informativas, que se extienden desde el 20 de octubre de 1998 hasta el 19 de enero de 1999, se resaltan algunas reflexiones del médico que fue testigo directo de lo que ocurrió el 11 de septiembre de 1973 en el Palacio de La Moneda. Cabe destacar que la traducción al árabe de este libro estuvo a cargo de tres autores marroquíes: Boughlaeb Al-Attar, Abderrahman El Omrani y Yamal Eddin Michbal. A este respecto, ilustramos el siguiente titular:

\section{يدنيأ رودافل يسل El último día de Salvador Allende. (Al-Ittihad Al-Ichtiraki, 2001/1999, p.7).}

Por su parte, Cuba destaca como el sexto país con mayores valores noticiosos; el periódico objeto de estudio dedica un total de 50 piezas comunicativas que aluden a este país caribeño. Por su parte Argentina aparece también como foco mediático importante; ostenta un total de 40 titulares noticiosos, o sea, el 6,42\% del corpus estudiado. En este mismo sentido, conviene destacar que en el caso de Argentina fue retratada, por una parte, como un país de grandes riquezas culturales. En concreto, hemos apreciado que una buena parte de las unidades comunicativas hacen referencia a José Luis Borges, una de las figuras más importantes de la literatura universal. Por otra parte, el diario objeto de estudio destaca este país como un socio privilegiado de Marruecos en la región latinoamericana.

Perú es otro de los países latinoamericanos con una mirada mediática particular. Este país acapara el 5,68\% 
del corpus estudiado. Conviene destacar que el análisis revela que la presencia informativa de este país andino ha sido recurrente, sobre todo, en la última década del siglo XX. Con respecto a la naturaleza de esas piezas informativas, hay que decir que el diario Al-Ittihad Al-Ichtiraki mostró una mayor referencialidad informativa a las tres siguientes dimensiones; primero, a los escandalosos acontecimientos que marcan el transcurso de la vida política del Gobierno de Fujimori (desde el 28 de julio de 1990 hasta el 21 de noviembre de 2000). En segundo lugar, al conflicto interregional que recibe el nombre de La Guerra del Cenepa o Conflicto del Alto Cenepa, que enfrentó a las fuerzas armadas del Perú y Ecuador durante los meses de enero y febrero de 1995. Por último, el diario objeto de estudio enfatiza el tema de la toma de la residencia del embajador japonés en Lima, el 17 de diciembre de 1996 en Lima.
Luego en su orden aparecen los siguientes países: Bolivia, 9 unidades comunicativas; Nicaragua y "Sudamérica, 8 unidades comunicativas respectivamente; Ecuador, 6 unidades comunicativas. En el extremo opuesto, hay otras áreas geográficas que denotan una débil referencialidad informativa. Así, El Salvador incluye apenas 5 unidades informativas; Haití, 4 unidades comunicativas; y Costa Rica, 3 unidades.

\section{Distribución total de las fuentes de información localizadas}

En este punto indagamos los distintos puntos a las que acude el periódico Al-Ittihad Al-Ichriraki para aprovisionarse de información latinoamericana. Respecto al corpus informativo que hemos analizado, la distribución de las fuentes es la siguiente: 


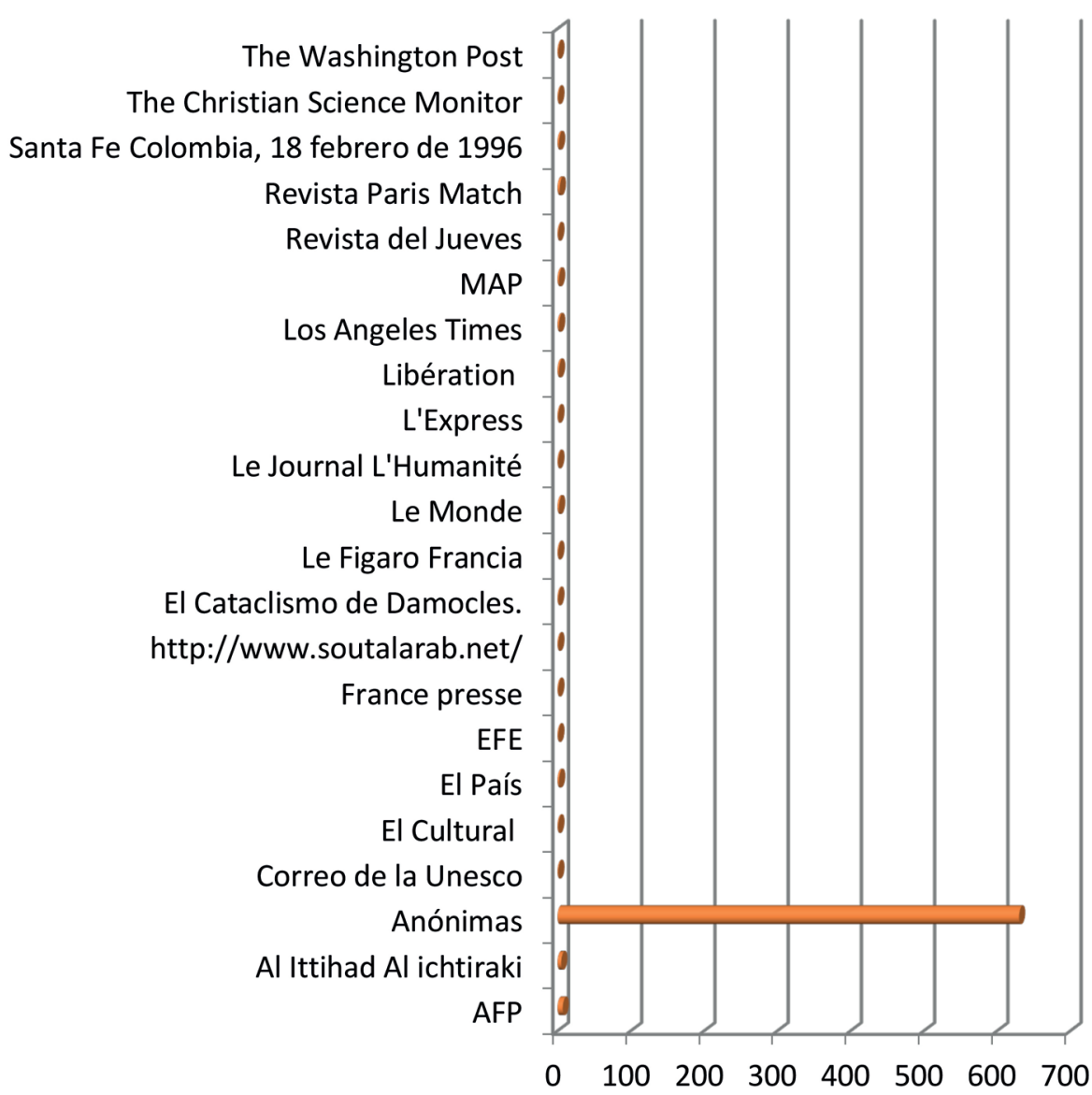

Gráfico 5. Distribución porcentual de las fuentes de información.

Fuente: elaboración propia.

El estudio de las fuentes informativas permite establecer las siguientes observaciones:

Una de las primeras aproximaciones que se impone es la idea de que, a la vista de los resultados obtenidos en el gráfico, se constata que de las 669 unidades informativas que constituyen el corpus analizado, un total de 630 carecen absolutamente de fuentes. En otras palabras, el 94,17\% de la muestra estudiada no posee ninguna fuente informativa. Este dato permite cuestionar la credibilidad de las informaciones publicadas por el periódico objeto de estudio sobre el subconti- nente latinoamericano. Este hecho se refuerza tomando en cuenta que apenas unas 5 unidades informativas son firmadas por el propio periódico. De ahí inferimos que el periódico objeto de estudio no dispone de suficientes recursos económicos como para enviar a sus propios corresponsales al subcontinente latinoamericano. El análisis muestra asimismo una escasa presencia de las unidades generadas por la agencia marroquí (MAP). En efecto, dicha agencia suma apenas dos piezas comunicativas.

En contrapartida, el estudio muestra una fuerte presencia de las agen- 
cias informativas europeas. Lo cual revela que el periódico objeto de estudio no disponía de una corresponsalía o una delegación de prensa, de hecho se abastecía de los servicios de las agencias para poder obtener la información del suceso latinoamericano. Así, la agencia francesa AFP ratifica aquí su liderazgo en un buen número de fuentes; es el primer motor de generación de noticias para Al-Ittihad Al-Ichtiraki, con un total de 7 titulares, y que supera la propia información suministrada por la agencia marroquí MAP. Este dato es significativo per se, y pone de manifiesto que la visión informativa de América Latina está mediada por terceros.

Además de dicha agencia, el análisis muestra que el diario objeto de estudio se abastece de otras fuentes francesas; tal es el caso de France Press, que genera una sola unidad informativa. El periódico objeto de estudio se aprovisiona asimismo de prestigiosos periódicos franceses, como las referencias a los periódicos: Revista Paris Match, con tres unidades; Le Figaro, con dos titulares; Le Monde; Le journal L'Humanité; L'Express; Libération. Estos datos ponen de relieve que las fuentes periodísticas francesas son las más usadas en el periódico Al-Ittihad Al-Ichtiraki.

Aparte de las referencias a los medios de Francia, también se han encontrado referencias a otras agencias de noticias europeas, aunque en menor medida, como la agencia española EFE, que se hizo sentir en una sola unidad comunicativa. Significativa- mente, el periódico estadounidense Washington Post se destaca como generador de una sola unidad informativa.

\section{Autores de las unidades comunica- tivas}

En este estudio identificamos los autores que contribuyeron con sus colaboradores a la presencia de unidades informativas relativas a América Latina. En el siguiente gráfico identificamos la nacionalidad de aquellos periodistas que se hicieron responsables de las unidades informativas:

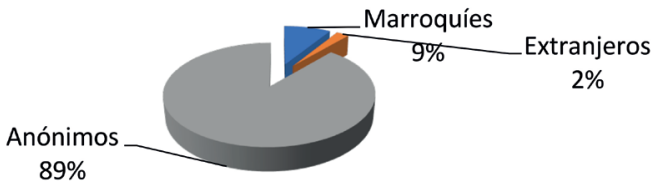

Gráfico 6. Nacionalidad de los autores.

Fuente: elaboración propia.

En el gráfico se observa, en términos generales, un claro predominio del anonimato en las informaciones sobre América Latina. De los 669 registros de prensa seleccionados entre 1991 y 2015, 594 aparecen sin firma. Esto pone de relieve que esas informaciones sobre América Latina son noticias preferentemente carentes del respaldo de una autoría. Otra de las observaciones que se impone es la idea de que se aprecia, al menos de forma significativa, una ausencia declarada de corresponsales marroquíes en el lugar donde ocurren estos hechos. Esta situación se debe, en muchos casos, a la falta de recursos. Sin embargo, llama la atención que algunas piezas informativas fueron firmadas por el propio director del órgano periodístico estudiado. Se trata de las publicaciones de 
Abdelhamid Jamahiri quien ha hecho una amplia cobertura al transcurso del Festival Mundial de la Juventud y los Estudiantes (FMJE), celebrado en Caracas en 2005. A este respecto, ilustramos el ejemplo del siguiente titular informativo:

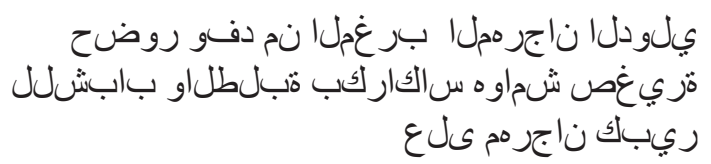

Una delegación marroquí participa en el Festival Mundial de la Juventud y los Estudiantes en Caracas: Pequeñas notas sobre un gran festival. (Al-Ittihad Al-Ichtiraki, 25/08/2005, p.4)

A esto hay que sumar que el diario Al-Ittihad Al-Ichtiraki recoge en sus páginas otras crónicas de viaje contadas por marroquíes que relatan sus sensaciones y sus reflexiones durante su estancia en algunos países latinoamericanos. En este mismo sentido, es preciso destacar que el diario Al-Ittihad Al-Itchtiraki recoge en la sección especial de Espacio de Ramadán de 2002 unas publicaciones del periodista Aziz Satori, tituladas Diario de un Marroquí en Colombia. A este propósito, Benabdelouahed Said afirma:

El testimonio ofrece una imagen de Colombia a través de las propias vivencias del autor. Es la imagen a la vez de los individuos que el autor va encontrando en su estancia y la de la vida pública que se observa en la calle y a través de los medios de comunicación colombianos. (2016, p.196)

La precisión anterior deja claro que se trata de un relato en el que se en- trecruzan lo periodístico y lo literario para resaltar una experiencia personal vivida por el propio autor durante su estancia en Colombia. El título de la obra resume sus principales ejes temáticos: Tiempo de Amor y Muerte. El amor en este caso es una sensación vivida por el autor protagonista por su amante colombiana y por las dos ciudades colombianas Cali y Bogotá. En cuanto al tema de la muerte en esta biografía, el autor lo transmite a través de sus "horrorosas" experiencias vividas en tiempos de las elecciones presidenciales, la lucha contra las drogas y el narcotráfico. A manera de ilustración veamos el siguiente titular:

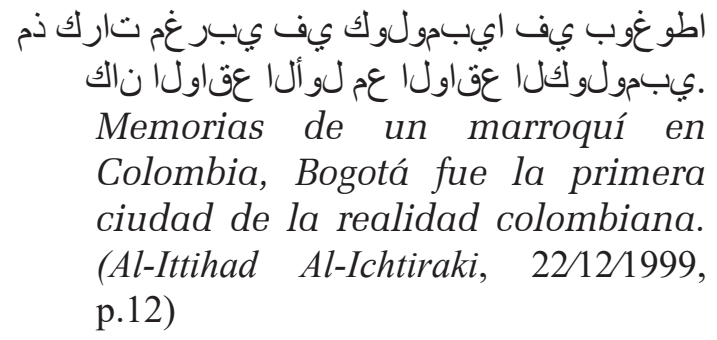

Por su parte, llama la atención que muchos autores figuran como traductores al árabe de obras literarias latinoamericanas. En esta misma línea, destacamos que el diario objeto de estudio reserva un buen espacio periodístico a las escrituras de Said Erroubai, quien expone, en la sección especial titulada espacio veraniego de 2012, varias unidades informativas en las que recopila una selección de relatos cortos del novelista y dramaturgo brasileño Paulo Coelho. Veamos el titular de la siguiente pieza comunicativa:

$$
\begin{aligned}
& \text { ومليوك ولبابل يرجي رمنل المك باتك }
\end{aligned}
$$

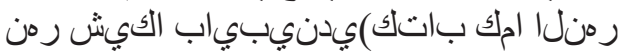

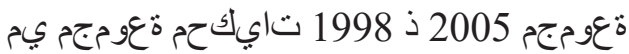




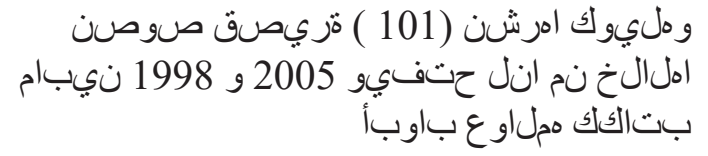

"El Río Que Fluye", un libro publicado entre 1998 y 2005 que recopila una selección de breves y profundos relatos de Paulo Coelho. (Al-Ittihad Al-Ichtiraki, 29-30/09/2012, p.10)

Junto a dichos autores, podemos mencionar a los autores Boughlaeb Al-Attar, Abderrahman, Yamal -Eddin Michbal, quienes aparecen como traductores al árabe del libro titulado EI Último Día de Salvador Allende cuyo autor es Óscar Soto Guzmán (Al Ittihad Al Ichtiraki, del el 20 de octubre de1998 hasta el 19 de enero de 1999). Conviene destacar que, gracias a las reflexiones de dichos autores, los lectores del diario Al-Ittihad Al-Ichtiraki tenían más posibilidades de percibir a América Latina como un espacio geográfico dotado de una gran riqueza cultural y artística. Desde nuestra perspectiva, consideramos que este dato es muy positivo porque permite reproducir una representación marroquí del acontecer latinoamericano.

\section{Conclusión}

Resumiendo; en base al análisis del tratamiento de la información publicada sobre América Latina en el periódico Al-Ittihad Al-Ichtiraki, se puede concluir que los resultados obtenidos ponen de relieve el posicionamiento ciertamente positivo de América Latina en las páginas del periódico objeto de estudio. Las evidencias encontradas en este trabajo son suficientes para probar esta afirmación. Así, los temas tratados y las referencias realizadas ponen de manifiesto que la tendencia es la de resaltar aspectos positivos. En efecto, el diario Al-Ittihad Al-Ichtirak dedica un amplio espacio informativo a noticias de interés literario y cultural. Se trata, pues, de un tratamiento equilibrado de alguna manera en su información sobre América Latina, al dedicar muchas unidades informativas a la dimensión cultural y artística. De ahí es difícil afirmar que los lectores de Al-Ittihad Al-Ichtiraki podían desarrollar una impresión negativa sobre América Latina. Por tanto, consideramos que el periódico tiende unos puentes interculturales a la otra vertiente atlántica intentando acercar, desde la esfera cultural, ambos espacios geográficos.

\section{Bibliografía}

Bastenier, M. (2011). El blanco móvil curso de periodismo con la experiencia de la escuela de El País, Madrid: Grupo Santillana de Ediciones.

Benabdelouahed, S. (2016), "La imagen de Colombia a partir de Tiempos del Amor y la Muerte de Aziz Satori». Actas del Coloquio Marruecos y América Latina: Historia Y Futuro, 15-16 marzo de 2006 Casablanca: Laboratorio de investigación: Marruecos y el Mundo Ibérico e iberoamericano: Facultad de Letras Ain Chock.

Berelson, B. (1952). Content analysis in communication research. New York: The Free Press. 
Edo, C. (2003). Periodismo Informativo e Interpretativo: El Impacto de Internet en la Noticia. Las Fuentes y los Géneros. Sevilla: Comunicación Social.

El Madkouri Maataoui, M. (2009) La Imagen del Otro en la Prensa. Madrid: Instituto Egipcio de Estudios islámicos.

Krippendorf, K. (1997). Metodología de análisis de contenido: teoría y práctica. Barcelona: Paidós. McCombs, M. (1996). «Influencia de las noticias sobre nuestras imágenes del mundo» en BRYANT, Jennings y ZILLMANN, Dolf (Comps.). Los efectos de los medios de comunicación: investigaciones y teorías. Barcelona: Paidós.

Peredeo Pombo, J. (2006). Periodismo Internacional: 10 Lecciones de Periodismo Especializado, Fragua, Madrid: Fragua.

Rodríguez Díaz, R. (2004). Teoría de la Agenda Setting: Aplicación a la Enseñanza Universitaria, Alicante: Observatorio Europeo de Tendencias Sociales.

Sofia Ramirez, A. (2005.). El texto de opinión de la prensa escrita. Las Palmas de Gran Canarias: Universidad Las Palmas de Gran Canarias.

Salomé Berrocal, G. (1998). Análisis básico de la prensa diaria: manual para aprender a leer periódicos. Madrid: Universitas.

Van Dijk, T. (2003). Ideología y discurso. Barcelona: Ariel.

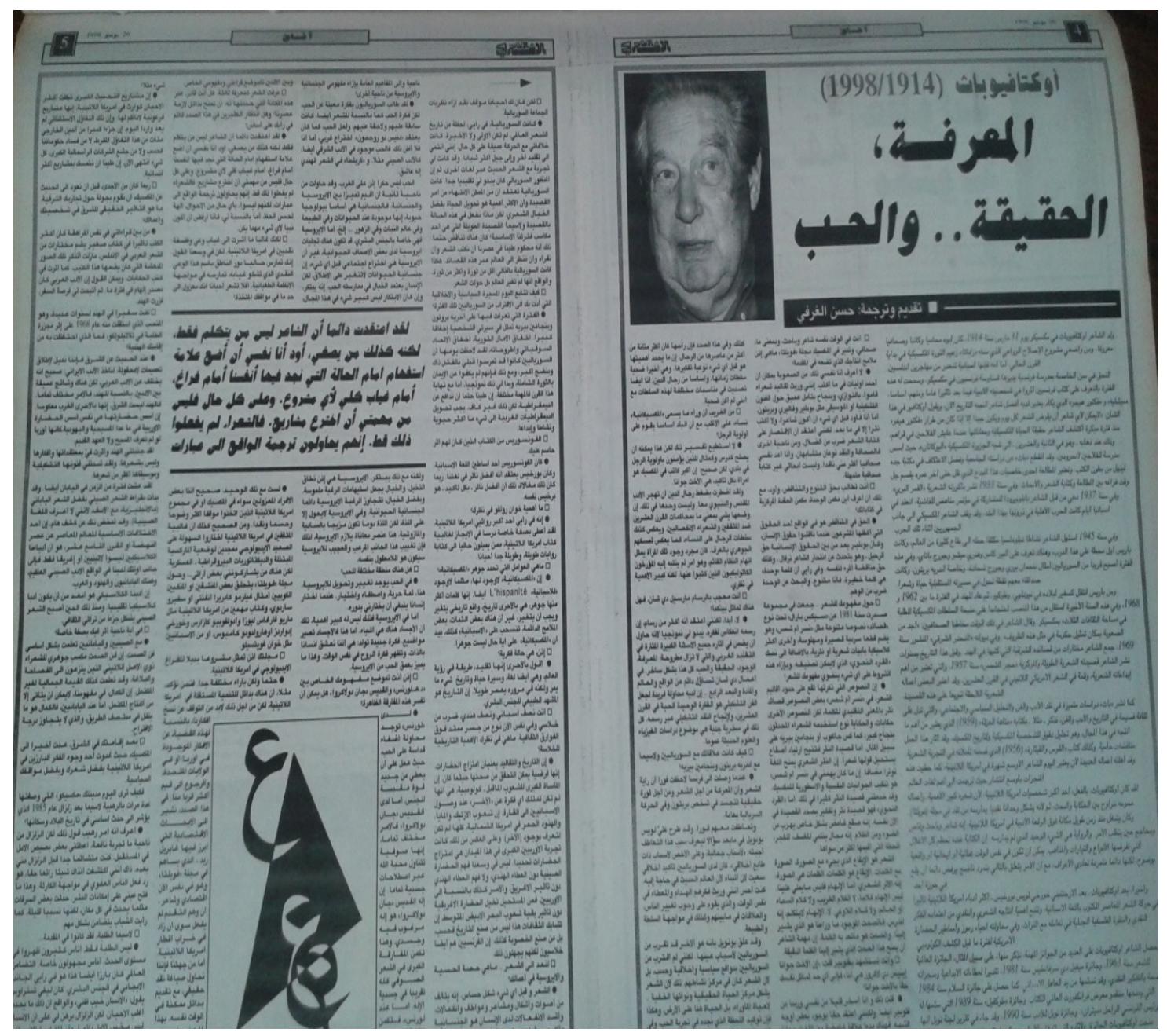

Ilustración 1. Al-Itihad Al-Ichtiraki ,26/06/1998, p.4. 